\title{
Glucose and ATP Levels in Pancreatic Islet Tissue of Normal and Diabetic Rats
}

\author{
Franz M. Matschinsky, Anthony S. Pagliara, Susan N. Stillings, and Barbara A. Hover \\ From the Edward Mallinckrodt Departments of Pediatrics and Pharmacology, Washington \\ University School of Medicine, St. Louis, Missouri 63110
}

A B S T R A C T It has been suggested that the hyperglucagonemia observed in diabetic animals and man may be due to an impairment of glucose uptake and metabolism by the $\alpha$-cells resulting in a decreased production of ATP. To test this hypothesis glucose, ATP, glucagon, and insulin were measured in pancreatic islets of normal and alloxan or streptozotocin diabetic rats. Two experimental approaches were used. In the first, the pancreas was perfused in vitro for assessing insulin and glucagon release due to $10 \mathrm{mM}$ amino acids with and without $5 \mathrm{mM}$ glucose. These perfusions were performed in the presence and absence of insulin. After perfusion, the pancreas was frozen and processed for analysis of islet glucose, ATP, insulin, and glucagon content. The second approach was to investigate the islet sucrose, urea, and glucose spaces together with ATP, insulin, and glucagon content in vivo in normal and in insulintreated and untreated streptozotocin diabetic rats.

Perfusion of the pancreas in vitro with $5 \mathrm{mM}$ glucose resulted in higher glucose content of normal islets than in alloxan and streptozotocin diabetic islets. Similarly in the in vivo studies, the intracellular glucose space of the streptozotocin diabetic islets was $30 \%$ the value found in normals. In the in vivo experiments, despite the relatively small intracellular glucose space of $\alpha$-cell islets, the ATP content of these islets was only $15-20 \%$ lower than the ATP content of normal islets. In the in vitro experiments, perfusion with glucose resulted in ATP contents of $\alpha$-cell islets and of normal mixed $\alpha$ - $\beta$-cell islets which were indistinguishable. However, the ATP

This work was presented in part in 1974 at the 34th Annual Meeting of the American Diabetes Association, Diabetes 23 (Suppl. 1): 340 .

Dr. Matschinsky is an Established Investigator of the American Diabetes Association and Dr. Pagliara is a recipient of a Research Career Development Award, AM-00003.

Received for publication 19 March 1976 and in revised form 4 June 1976. content of $\alpha$-cell islets was maintained for prolonged periods in the absence of glucose in contrast to mixed islets, composed primarily of $\beta$-cells, in which the ATP level decreased by $45 \%$ when glucose-free medium was perfused for sustained periods. Finally, insulin infused in high concentrations or administered to the diabetic animal had no effect on the glucose spaces or the ATP contents of normal or $\alpha$-cell islets.

It can be calculated that in vivo the intracellular glucose level of islets from streptozotocin treated rats is approximately $15 \mathrm{mM}$. Since in normals an extracellular glucose concentration of this magnitude inhibits stimulated glucagon release completely, it would seem unlikely that a lack of intracellular glucose is the cause of the apparent glucose "blindness" of the $\alpha$-cells in diabetes. In fact, in perfusion studies as little as $2.5 \mathrm{mM}$ free intracellular glucose was sufficient to suppress glucagon secretion from diabetic $\alpha$-cells. The results of the ATP measurements clearly eliminate a possible energy deficit of diabetic $\alpha$-cells as cause of the apparent glucose resistance of $\alpha$-cells.

\section{INTRODUCTION}

The hyperglucagonemia that occurs in severe diabetes in man, and in animals made diabetic with alloxan or streptozotocin, is not suppressed by high glucose, but is suppressed after insulin treatment (1). On the basis of these observations, together with in vitro studies utilizing isolated islets, in which metabolic poisons seemed to interfere with glucose inhibition of glucagon secretion $(2,3)$, it has been suggested that the hyperglycemic suppression of glucagon release in the normal islet results from enhanced glucose transport with a subsequent increase in energy metabolism within the $\alpha$-cell, and that the glucose metabolism of these cells is an insulin-requiring process. Similarly, the lack of glucose suppression of glucagon release in the diabetic state in vivo has been attributed to a 


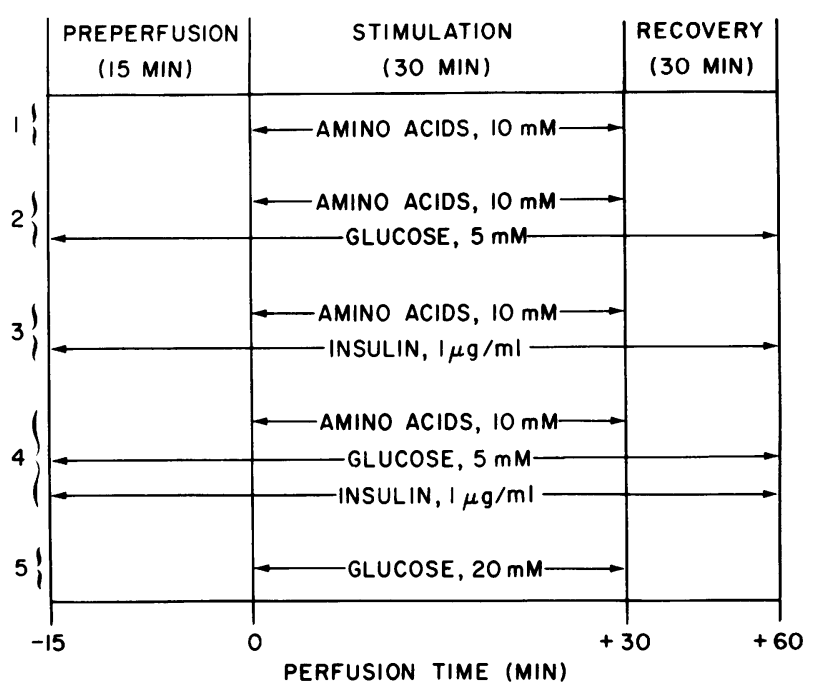

FIGURE 1 Experimental protocol for perfusion studies. The pancreas was perfused for a total of $75 \mathrm{~min}$ with buffer alone, glucose, and amino acids as indicated in Protocols $1-5$. The pancreas was then rapidly frozen at $t_{+60}$ and processed as indicated in the text.

decrease in glucose uptake by the $\alpha$-cell with a concomitant decrease in ATP availability (4).

In a previous communication form this laboratory (5), it was demonstrated in both alloxan and streptozotocin diabetic rats that: $(a)$ basal glucagon release from the isolated perfused pancreas (measured in the absence of an $\alpha$-cell stimulus or inhibitor) was extremely low, about $1 / 10$ the basal rates seen in controls; (b) the $\alpha$-cells of both diabetic prototypes responded with a biphasic glucagon release to stimulation by an amino acid mixture; $(c)$ the $\alpha$-cell response to amino acids was reduced after both streptozotocin and alloxan as compared to controls; (d) glucose ( $5 \mathrm{mM}$ ) was a potent inhibitor of amino acid-induced glucagon secretion in both experimental types of diabetes in the virtual absence of insulin secretion; and $(e)$ in alloxan diabetes $\alpha$-cell stimulation by amino acids was inhibited by high levels of exogenous insulin, whereas glucagon secretion by the perfused pancreas of streptozotocin diabetic rats was resistant to insulin action under these conditions. It was concluded from this study that the basic mechanisms underlying modulation of glucagon secretion by glucose in vitro is largely insulin independent and that factors extrinsic to the pancreatic islets are the primary cause for the hyperglucagonemia observed in vivo.

The present communication is an extension of the above study. It was the objective during this part of our investigation to obtain basic information on parameters of energy metabolism of pancreatic $\alpha$-cells by direct chemical analysis, rather than through indirect means. Glucose and ATP concentrations were determined in islets of normal, streptozotocin, and alloxan diabetic animals in an attempt to further elucidate the mechanism by which glucose might inhibit glucagon secretion. Quantitative histochemical methods were applied for this purpose, which allowed us to perform such measurements in islets from the pancreas rapidly sampled in vivo or after extracorporeal organ perfusion.

\section{METHODS}

\section{Studies with the isolated perfused pancreas}

The general preparation of the animals, the induction of diabetes by alloxan or streptozotocin, and the procedural details of the extracorporeal perfusion of the pancreas used in the biochemical portion of this study, have been presented previously, together with the data on $\alpha$ - and $\beta$-cell secretory functions (5). The five different experimental protocols used in the perfusion studies are summarized in Fig. 1. For further details, the preceeding paper may be consulted (5). After termination of the perfusion, the pancreas, with the spleen attached, was quickly separated from the stomach and duodenum and frozen in Freon-12 (Virginia Chemicals, Inc., Portsmouth, Va.), cooled to its freezing point with liquid nitrogen. The frozen samples were stored at $-70^{\circ} \mathrm{C}$ until processed for quantitative histochemistry (see below).

\section{In vivo experiments}

Animal preparation. Male Sprague-Dawley rats weighing 300-400 g, fed ad libitum with Purina rat chow (Ralston Purina Co., Inc., St. Louis, Mo.) and water, were used in all experiments. Diabetes was induced by streptozotocin (70 $\mathrm{mg} / \mathrm{kg}$ i.v.). $1 \mathrm{wk}$ after streptozotocin injection, one-half of the group was treated with insulin. The treated group received 5 IU of NPH insulin subcutaneous between 4 and 6 p.m. daily and $1.5 \mathrm{IU}$ in the morning, between 9 and $10 \mathrm{a} . \mathrm{m}$. On this regimen, which was continued for $2-3 \mathrm{wk}$, the animals decreased their daily urine volume and fluid intake and gained weight, whereas the nontreated diabetic animals lost weight continuously. At the time of sacrifice, the weight of the normal animals was $394 \pm 6 \mathrm{~g}(n=8)$, that of the insulin-treated diabetic animals $288 \pm 6 \mathrm{~g}(n=8)$, and that of the nontreated diabetic animals $224 \pm 6 \mathrm{~g}(n=8)$. The animals received their last insulin $14 \mathrm{~h}$ before sacrifice. Unlike the in vitro study where all animals were fasted (5), all animals in the in vivo study were allowed to feed to prevent hypoglycemic seizures, which were common in the insulin-treated group when these animals were fasted.

Blood and pancreas sampling and special treatment before sampling. Animals received atropine $(0.1 \mathrm{mg} / \mathrm{kg}$ i.p.) and were anesthetized $30 \mathrm{~min}$ later by pentobarbital $(30 \mathrm{mg} / \mathrm{kg}$ i.p.). The abdominal cavity was opened and the pancreas exposed. Heparin (30 USPU iv/kg body weight) was injected into the inferior vena cava together with the extracellular marker sucrose $(0.1 \mathrm{ml}$ of $1.5 \mathrm{M}$ i.v./kg body weight) 5 min before sampling of the pancreas. The pancreas, with the spleen still attached, was quickly excised and frozen in Freon-12, cooled to its freezing point with liquid nitrogen. Blood was sampled from the pool accumulating in the peritoneal cavity after the pancreas had been removed. The blood was injected into tubes containing $500 \mathrm{KIU} / \mathrm{ml}$ Trasylol (FBA Pharmaceuticals, Inc., New York) and $1.25 \mathrm{mg}$ EDTA/ $\mathrm{ml}$, and was kept on ice for no longer than $30 \mathrm{~min}$. The blood was then separated by centrifugation and the 
plasma stored at $-20^{\circ} \mathrm{C}$ until assayed. Insulin and glucagon were determined in plasma and islet samples by radioimmunoassay procedures described previously $(5,6)$.

Preparation of the pancreas for histochemical analysis. Sections of the pancreas were cut at $-20^{\circ} \mathrm{C}$ in the cryostat $30 \mu \mathrm{m}$ thick and were submitted to freeze drying for three days at $-40^{\circ}$ to $-35^{\circ} \mathrm{C}$ and then stored under vacuum at $-20^{\circ} \mathrm{C}$. Islets were then dissected with the aid of a stereomicroscope at low magnification without prior staining in a room that provided low humidity $(50 \%)$ and constant temperature $\left(18^{\circ} \mathrm{C}\right)$. The weights of the specimens were obtained with the quartz fiber fishpole balance $(7,8)$.

Chemical analytical procedures. Plasma glucose, sucrose, and urea measurements were performed by fluorometric enzymatic assays. Islet contents of glucose, sucrose, urea, and ATP were determined by enzymatic fluorometry in combination with enzymatic cycling and an oil well technique, to gain the necessary sensitivity. Principles and procedural details of the methods have been described previously $(7,8)$, except for urea. The present procedure is a modification of a method to be published elsewhere. ${ }^{1}$ The enzymatic assay for urea is based on the liberation of $\mathrm{NH}_{3}$ from urea by urease, followed by the recording of the triphosphopyridine nucleotide (TPNH) ${ }^{2}$ dependent amination of $\alpha$ keto-glutarate by glutamic acid dehydrogenase. Details of this latter method are given below. To measure urea in plasma $1-3 \mu \mathrm{l}$ of plasma are added to $1 \mathrm{ml}$ of the following reagent: Tris- $\mathrm{HCl}$ buffer, $50 \mathrm{mM}$ pH 7.7; ADP, 0.1 $\mathrm{mM} ; \alpha$-keto-glutarate, $5 \mathrm{mM}$; TPNH, $25 \mu \mathrm{M}$; and nicotinamide, $20 \mathrm{mM}$. The two enzymes were added separately; $65 \mu \mathrm{g} / \mathrm{ml}$ of glutamic acid dehydrogenase as the first step to allow correction for ammonia present in the plasma and reagent, followed by the addition of urease $(3.2 \mu \mathrm{g} / \mathrm{ml})$ in a second step for the specific assay of urea. Urea standards ranging from 1.5 to $9.5 \mathrm{nmol}$ were processed in the same way. The microassay was performed with an oil well method (8). Single islet slices were extracted under oil with 0.15 $\mu$ l of $0.03 \mathrm{~N} \mathrm{NaOH}$ for $30 \mathrm{~min}$ at $25^{\circ} \mathrm{C}$. To the droplet of alkaline extract was added $0.15 \mu \mathrm{l}$ of a reagent containing $150 \mathrm{mM}$ Tris-HCl buffer, $\mathrm{pH} 7.36 ; 0.2 \mathrm{mM}$ ADP, $10 \mathrm{mM}$ $\alpha$-keto-glutarate, $40 \mathrm{mM}$ nicotinamide, $150 \mu \mathrm{M}$ TPNH, $130 \mu \mathrm{g} / \mathrm{ml}$ of glutamic acid dehydrogenase, and $6.35 \mu \mathrm{g} / \mathrm{ml}$ of urease. Addition of the reagent to the alkaline tissue suspension resulted in a final $\mathrm{pH}$ of 7.7. To allow correction for the $\mathrm{NH}_{3}$ contamination in the reagent and tissue, blanks were obtained by omitting the urease from the reagent. After incubating for $1 \mathrm{~h}$ at $25^{\circ} \mathrm{C}, 1.3 \mu \mathrm{l}$ of $0.2 \mathrm{~N}$ $\mathrm{HCl}$ was added and the incubation continued for $15 \mathrm{~min}$ to destroy residual TPNH. The TPN formed in the enzymatic assay was measured by enzymatic cycling $(7,8)$. For this purpose, the droplet was transferred quantitatively to 50 $\mu l$ of cycling reagent (8). The two cycling enzymes were adjusted to result in an amplification of about 2,000-fold The 6-P-gluconate formed in the process of cycling was measured by enzymatic fluorometry $(7,8)$. Urea standards in the range from $1-5 \mathrm{pmol}$ and introduced at the weak alkali step were processed in the same fashion.

Determination of the urea, sucrose, total, and intracellular glucose spaces of pancreatic islets. Urea, sucrose, and glucose spaces of the normal, insulin-treated and untreated diabetic islets were calculated from the serum and islet concentrations of the respective substances as follows: $C_{l} \times 0.92 / C_{s}=$ islet space (liters $/ \mathrm{kg}$ dry tissue), where: $C_{l}$ $=$ islet concentration $(\mathrm{mmol} / \mathrm{kg}$ dry tissue $), \mathrm{C}_{\mathrm{s}}=$ serum con-

\footnotetext{
${ }^{1}$ Ramaiah, A., M. Law, and O. H. Lowry. To be published.

${ }^{2}$ Abbreviation used in this paper: TPNH, triphosphopyridine nucleotide, reduced form.
}

TABLE I

Plasma Glucose, Insulin, and Glucagon in Normal and Streptozotocin Diabetic Animals Used in the In Vivo Studies*

\begin{tabular}{lccccc}
\hline & $n$ & Body wt & Glucose & Insulin & Glucagon \\
\hline & & $g$ & $m M$ & $\mu U / m l$ & $p g / m l$ \\
Normal & 8 & $394 \pm 6$ & $10.0 \pm 0.3$ & $54 \pm 4$ & $120 \pm 8$ \\
Diabetic & 8 & $224 \pm 6$ & $32.5 \pm 1.9$ & $2 \pm 0.4$ & $293 \pm 42$ \\
Diabetic & & & & & \\
$\quad+$ insulin & 8 & $288 \pm 6 \ddagger$ & $23.4 \pm 3.2 \ddagger$ & $50 \pm 16 \ddagger$ & $200 \pm 20$ \\
$P \S$ & & $<0.01$ & $<0.001$ & $<0.001$ & $<0.01$ \\
& & & & NS & \\
& & & & without & \\
& & & & insulin & \\
& & & & &
\end{tabular}

* All values represent the mean \pm SEM.

\$ Significantly different, comparing diabetic and diabetic + insulin, $P<0.01$ for weight, $P<0.05$ for glucose, and $P$ $<0.001$ for insulin.

$\$$ Degree of significance of the difference of plasma values of diabetic animals as compared to normals in the respective study.

centration (mmol/liter), and $0.92=$ correction for plasma solids. Since sucrose is confined to the extracellular space, the intracellular glucose space is the difference between the total glucose space minus the sucrose space. All spaces are expressed in nanoliters per microgram of dry tissue.

\section{RESULTS}

Criteria for defining diabetes. The animals used in this project were defined as being diabetic when the plasma glucose in the untreated state was greater than $6 \mathrm{SD}$ from the mean of the corresponding control animals, as previously discussed in detail (5). These animals also demonstrated markedly depressed plasma insulin and significantly elevated plasma glucagon levels (see Table I for the in vivo study and Ref. 5 for the perfusion study). In the in vivo study, the diabetic animals, whether treated with insulin or not, had significantly higher plasma glucose than controls and elevated plasma glucagon levels. The plasma glucagon of the insulin treated animals was lower than that of the untreated, but this difference was not statistically significant. Insulin significantly lowered the plasma glucose of the treated animals. In the untreated diabetics, plasma insulin was barely detectable, while in the treated diabetics, it was indistinguishable from the plasma insulin of the controls. The severity of the diabetes induced by alloxan and streptozotocin is further documented by the results of the perfusion study previously published (5).

Insulin and glucagon content of islets sampled in vivo or from the isolated perfused pancreas of normal and diabetic rats. Analysis of insulin and glucagon 
content of microdissected islets from the pancreas, sampled in vivo or at the termination of the perfusion experiments, gave further evidence that we were dealing with practically pure $\alpha$-cell islets in the diabetic animals (Table II). Total insulin content in the islets of the diabetic animals was $5-6 \%$ of the normal, while the ratio of total glucagon content between normal mixed $\alpha$ - and $\beta$-cell islets and that of the $\alpha$-cell islets varied between 4 and 10 (Table II). This ratio is further evidence that the tissue being analyzed in the diabetic pancreas contained primarily $\alpha$-cells, since it has been previously demonstrated morphologically that the $\alpha$-cell mass of the rat pancreas consists of $10-25 \%$ of the total islet cell mass $(9,10)$. Preliminary determinations of the islet volume revealed a decrease in diabetes as defined here to at least one-third of the control value (11), consistent with the results published by others (9).

\section{In vitro studies}

Glucose content of islets from the isolated pancreas of normal and diabetic rats. The glucose contents of microdissected islets obtained by perfusing the pancreas with the $10-\mathrm{mM}$ amino acid mixture were similar in normal and both diabetic prototypes and increased markedly after perfusions with $5 \mathrm{mM}$ glucose (compare Protocols 1 and 2, Table II). The total islet glucose content with a glucose load of $5 \mathrm{mM}$ was significantly smaller in alloxan and streptozotocin islets, than in normals (normal 18.1 \pm 1.1 , alloxan 15.2 \pm 0.8 , and streptozotocin $13.6 \pm 1.1 \mathrm{mmol} / \mathrm{kg}$ dry tissue, $P<0.001$ for both diabetic prototypes vs. normal). After perfusions with insulin but without added glucose (Protocol 3, Table II), the total glucose contents of the islets were low and did not differ significantly from aglycemic perfusions without insulin (compare

TABLE II

Glucose, ATP, Glucagon, and Insulin Levels of Islets from the Isolated Perfused Pancreas of Normal and Diabetic Rats*

\begin{tabular}{|c|c|c|c|c|c|c|c|}
\hline Condition & $n$ & Glucose & & ATP & & Glucagon & Insulin \\
\hline & & \multicolumn{4}{|c|}{ mmollkg dry tissue } & ng/ug dry tissue & $\mu U / \mu y$ dry tissue \\
\hline Protocol 1 & & & $P \ddagger$ & & $P \ddagger$ & & \\
\hline Normal & 3 & $1.7 \pm 0.3$ & - & $7.6 \pm 0.5$ & - & $2.2 \pm 0.5$ & $1,563 \pm 157$ \\
\hline Alloxan & 9 & $2.0 \pm 0.3$ & - & $13.7 \pm 0.9^{\prime \prime}$ & - & $14.0 \pm 1.7$ & $66 \pm 21^{\prime \prime}$ \\
\hline Streptozotocin & 6 & $3.2 \pm 0.8$ & - & $13.3 \pm 0.9^{\prime \prime}$ & - & $21.2 \pm 1.7^{\prime \prime}$ & $87 \pm 18^{\prime \prime}$ \\
\hline \multicolumn{8}{|l|}{ Protocol 2} \\
\hline Normal & 4 & $18.1 \pm 1.1$ & $<0.001$ & $13.4 \pm 0.8$ & $<0.01$ & $4.3 \pm 0.8$ & $1,433 \pm 71$ \\
\hline Alloxan & 11 & $15.2 \pm 0.8^{\prime \prime}$ & $<0.001$ & $13.9 \pm 0.5$ & NS & $15.8 \pm 1.6^{\prime \prime}$ & $68 \pm 19^{\prime \prime}$ \\
\hline Streptozotocin & 6 & $13.6 \pm 1.1^{\prime \prime}$ & $<0.001$ & $11.7 \pm 0.7$ & NS & $17.2 \pm 0.7^{\prime \prime}$ & $86 \pm 10^{\prime \prime}$ \\
\hline Protocol 3 & & & $P \S$ & & $P \S$ & & \\
\hline Normal & 5 & $1.2 \pm 0.1$ & NS & $7.5 \pm 0.3$ & NS & $2.8 \pm 0.2$ & $1,540 \pm 82$ \\
\hline Alloxan & 8 & $3.0 \pm 0.4^{\prime \prime}$ & NS & $13.1 \pm 0.4^{\prime \prime}$ & NS & $11.9 \pm 2.0^{\prime \prime}$ & $44 \pm 7^{11}$ \\
\hline Streptozotocin & 6 & $3.8 \pm 0.7^{\prime \prime}$ & NS & $13.0 \pm 0.8^{\prime \prime}$ & NS & $18.9 \pm 1.2^{\prime \prime}$ & $60 \pm 8^{\prime \prime}$ \\
\hline \multicolumn{8}{|l|}{ Protocol 4} \\
\hline Normal & 3 & $18.6 \pm 1.0$ & NS & $15.0 \pm 1.5$ & NS & $2.4 \pm 0.1$ & $1,295 \pm 71$ \\
\hline Alloxan & 5 & $15.1 \pm 1.0$ & NS & $15.6 \pm 0.2$ & NS & $18.6 \pm 1.3^{\prime \prime}$ & $35 \pm 10^{\prime \prime}$ \\
\hline Streptozotocin & 6 & $12.8 \pm 1.1^{\prime \prime}$ & NS & $14.4 \pm 0.8$ & NS & $20.8 \pm 1.4^{\prime \prime}$ & $56 \pm 20^{\prime \prime}$ \\
\hline \multicolumn{8}{|l|}{ Protocol 5} \\
\hline Normal & 3 & $1.8 \pm 0.1$ & - & $7.1 \pm 1.4$ & - & $3.1 \pm 0.7$ & $1,499 \pm 124$ \\
\hline Alloxan & 6 & $3.1 \pm 0.4$ & - & $14.5 \pm 1.2^{\prime \prime}$ & - & $16.1 \pm 2.3^{\| \prime}$ & $81 \pm 28^{\prime \prime}$ \\
\hline Streptozotocin & 3 & $4.2 \pm 1.2$ & - & $12.4 \pm 0.5^{\| \prime}$ & - & $19.8 \pm 3.4^{\prime \prime}$ & $104 \pm 8^{\prime \prime}$ \\
\hline
\end{tabular}

* Glucose, ATP, glucagon, and insulin were measured in microdissected islet pieces from freeze-dried pancreas sections. The pancreas was rapidly frozen after $75 \mathrm{~min}$ of perfusions according to Protocols 1-5 (Fig. 2). The means \pm SEM are recorded. For each pancreas, six islets were analyzed for each parameter.

\$ Degree of significance between perfusions with and without glucose (comparison of Protocol 1 with 2). $\S$ Degree of significance between perfusions with and without insulin (comparison of Protocol 1 with 3 and 2 with 4 ).

"Significantly different $(P \leqq 0.05)$ from the normal pancreas within each perfusion Protocol. 
TABLE III

Plasma and Islet Concentrations of Glucose, Sucrose, and Urea in Normal, Untreated, and Insulin-Treated Diabetic Rats In Vivo*

\begin{tabular}{|c|c|c|c|c|c|c|c|}
\hline \multirow[b]{2}{*}{ Condition } & \multirow[b]{2}{*}{$n$} & \multicolumn{3}{|c|}{ Plasma } & \multicolumn{3}{|c|}{ Islet } \\
\hline & & Glucose & Sucrose & Urea & Glucose & Sucrose & Urea \\
\hline & & \multicolumn{3}{|c|}{$m \cdot M$} & \multicolumn{3}{|c|}{ mmolkg dry tissue } \\
\hline Normal & 8 & $10.0 \pm 0.3 \nmid$ & $13.3 \pm 0.5$ & $6.6 \pm 0.2$ & $28.8 \pm 2.0$ & $8.65 \pm 0.62$ & $17.5 \pm 1.2$ \\
\hline Diabetic & 8 & $32.5 \pm 1.9 \S$ & $14.1 \pm 0.5$ & $13.1 \pm 0.9 \S$ & $43.2 \pm 3.8 \S$ & $9.50 \pm 1.15$ & $30.8 \pm 2.8 \S$ \\
\hline \multirow{2}{*}{\multicolumn{8}{|c|}{ Diabetic }} \\
\hline & 8 & $23.4 \pm 3.2 \S$ & $12.0 \pm 0.5$ & $8.6 \pm 0.7 \S$ & $31.6 \pm 3.2$ & $9.04 \pm 0.73$ & $24.8 \pm 3.3$ \\
\hline
\end{tabular}

* Animals were given $0.1 \mathrm{ml} / 100 \mathrm{~g}$ body wt of $1.5 \mathrm{M}$ sucrose i.v. $5 \mathrm{~min}$ before blood drawing and pancreatectomy.

$\$$ Mean \pm SEM of eight animals in each group.

$\S$ Significantly different $(P<0.05)$ from the normal animals.

Protocols 1 and 3). Furthermore, insulin ( $1 \mu \mathrm{g} / \mathrm{ml})$, perfused along with the amino acid mixture and $5 \mathrm{mM}$ glucose, had no effect on increasing the glucose content of the normal or diabetic islets, and the islet glucose content was nearly identical to that observed in perfusions without insulin (compare Protocols 2 and 4).

In the absence of glucose in the perfusion media, total glucose content in the diabetic islets, although low, was approximately $2-2.5$ times higher than normal (e.g. about 1.5 vs. $3.4 \mathrm{mmol} / \mathrm{kg}$ dry tissue). Why the islets should continue to contain measurable amounts of free glucose, after $\mathbf{7 5}$ min of aglycemic perfusion, is not clear. First, the method used here to measure glucose might react with some form of bound glucose, which is mobilized by the mild acidic treatment in preparation of the specific enzymatic microassay (8). It is unlikely that the glycogen is the source of bound glucose, since the glycogen levels of the islets are low (8). Second, the higher glucose content in the $\alpha$-cell islets may be explained by impeded diffusion of free glucose out of the $\alpha$-cell. The glucose pool to be dissipated is substantial, due to the prolonged and excessive hyperglycemia in vivo (see below).

Perfusion with $20 \mathrm{mM}$ glucose for $30 \mathrm{~min}$, followed by aglycemic perfusion for $30 \mathrm{~min}$, resulted in islet glucose concentrations which were indistinguishable from perfusions with the $10-\mathrm{mM}$ amino acid mixture alone, indicating that the 30 -min perfusion with the amino acid mixture had no effect on the basal glucose content of the islets. Again, the diabetic islets had significantly more glucose than the normal (normal 1.8 \pm 0.1 , alloxan $3.1 \pm 0.4$, and streptozotocin $4.2 \pm 1.2, P<0.05$, for both diabetic prototypes vs. normal; Protocol 5, Table II).

ATP content of normal and diabetic islets from the perfused pancreas. After pancreas perfusions without glucose, the ATP content of normal islets was significantly less than that found in $\alpha$-cell islets of alloxan and streptozotocin diabetic animals (normal 7.6 \pm 0.5 , alloxan diabetic $13.7 \pm 0.9$, and streptozotocin diabetic $13.3 \pm 0.9, P<0.001$ for both diabetic prototype vs. normal; Protocol 1, Table II). Addition of $5 \mathrm{mM}$ glucose to the perfusate significantly increased the ATP content of the normal islets $(7.6 \pm 0.5$ without glucose to $13.4 \pm 0.8 \mathrm{mmol} / \mathrm{kg}$ dry tissue with glucose, $P<0.001$ ), but had no effect on ATP content of $\alpha$-cell islets (compare Protocols 1 and 2, Table II). The increase in ATP in the normal islets, with glucose in the perfusion media, attained the level of that observed in the diabetic islets with or without glucose in the perfusate.

Addition of insulin to the perfusate, in the presence or absence of glucose, had no significant effect on the ATP content of normal or diabetic islets. (Compare Protocols 1 and 3, and 2 and 4, Table II). Although not significant, there was a tendency towards elevated ATP levels when normal and diabetic pancreases were perfused with glucose plus insulin (compare Protocols 2 and 4, Table II).

Perfusion with $20 \mathrm{mM}$ glucose for $30 \mathrm{~min}$, followed by aglycemic perfusion for $30 \mathrm{~min}$, resulted in islet ATP concentrations which were indistinguishable from those observed with the $10-\mathrm{mM}$ amino acid mixture, suggesting that the amino acids had little effect in the maintenance of the ATP content of normal or diabetic islets (Protocol 5, Table II).

\section{In vivo studies}

Concentrations of sucrose, urea, and glucose in pancreatic islets of normal, streptozotocin diabetic, and insulin-treated diabetic rats. Plasma glucose, sucrose, and urea concentrations 5 min after i.v. su- 


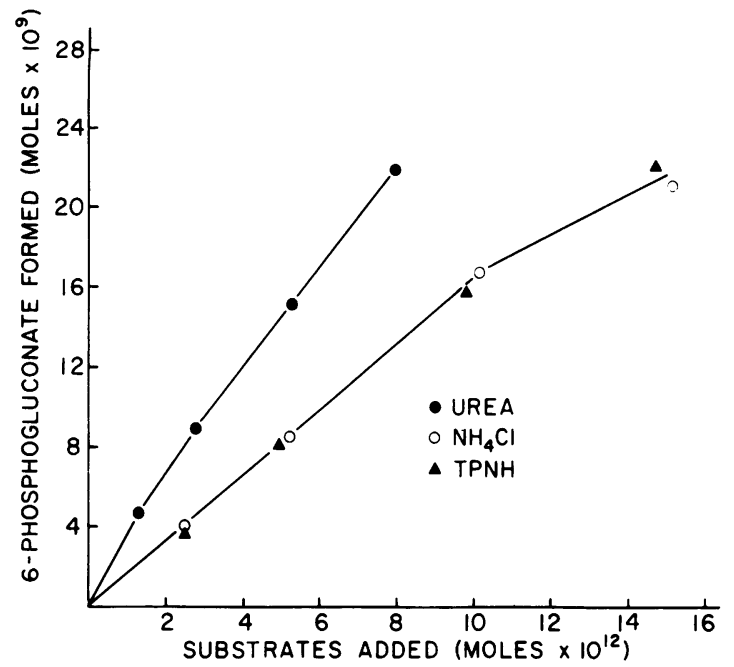

FIGURE 2 6-P-Gluconate formed in the microassay for urea. The ordinate records the final yield of product from different amounts of urea, $\mathrm{NH}_{4} \mathrm{Cl}$, or TPNH shown on the abscissa. Each point represents the mean of triplicate analyses. Standard errors are not indicated since they fall within the dimensions of the symbols. Urea and $\mathrm{NH}_{4} \mathrm{Cl}$ were introduced at the weak alkali step, whereas TPNH was added with the cyclic reagent. Amplification in this experiment was 1600 fold. The reagent blank in this assay due to $\mathrm{NH}_{3}$ contaminations and nonspecific fluorescence was equivalent to $4 \mathrm{pmol}$ of $\mathrm{NH}_{4} \mathrm{Cl}$.

crose administration to normal, untreated, and insulintreated diabetic animals are given in Table III. Plasma glucose in the normal rats was $10.0 \pm 0.3$, as compared to $32.5 \pm 1.9$ in the untreated diabetic and $23.4 \pm 3.2 \mathrm{mM}$ in the insulin-treated diabetic animals (both diabetic groups significantly different from controls, $P<0.001$, while the plasma glucose of the treated vs. the untreated diabetic rats was significant at the $P<0.05$ level). Plasma sucrose was the same in the three groups. Plasma urea was twofold higher in the untreated diabetics as compared to normals (13.1 \pm 0.9 vs. $6.6 \pm 0.2 \mathrm{mM}$, respectively, $P<0.001$ ), while the plasma urea of the treated diabetic animals was only slightly elevated as compared to control $(8.6 \pm 0.7$ vs. $6.6 \pm 0.2 \mathrm{mM}, P<0.05)$. The markedly elevated urea in the untreated diabetics most likely reflects a significant degree of dehydration resulting from the glycosuria and concomitant osmotic diuresis which was returned towards normal with insulin therapy (urea in untreated diabetics $13.1 \pm 0.9$ vs. treated diabetics $8.6 \pm 0.7 \mathrm{mM}, P<0.001$ ).

The islet glucose content of the untreated diabetic animals was significantly higher than that of both normal and treated diabetics (normal $28.8 \pm 2.0$, treated diabetic $31.6 \pm 3.2$, and untreated diabetic $43.2 \pm 3.8$ $\mathrm{mmol} / \mathrm{kg}$ dry tissue, $P<0.05$ treated diabetic vs. untreated diabetic) (Table III). No significant differences were observed in islet sucrose content among the three groups. Urea content in the normal islets was $17.5 \pm 1.2$ as compared to $30.8 \pm 2.8$ in the untreated diabetic $(P<0.001)$ and $24.8 \pm 3.3 \mathrm{mmol} / \mathrm{kg}$ dry tissue in the insulin-treated group $(P<0.05)$. The islet urea content in the treated animals was intermediate between the normal and untreated animals, but was not significantly different from either (Table III). The microassay for urea was fairly linear and recovery was nearly quantitative as compared to $\mathrm{NH}_{4} \mathrm{Cl}$ or reduced TPN (Fig. 2). Tissue blanks (not shown) amounted to $28 \%$ of the urea content in normal islets and proportionately less in the islets of diabetics (16\% in treated and $15 \%$ in untreated diabetics).

Sucrose, urea, and glucose spaces of islets in normal, untreated, and insulin-treated diabetic rats. Utilizing the plasma and islet concentrations of sucrose, urea, and glucose, the respective distributions of these substances in the tissue spaces were calculated (Table IV). The islet sucrose and urea spaces of the three groups were similar, while the total and intracellular glucose spaces of the normal islets were the largest (Table IV). Values obtained here for sucrose space agree with results obtained in mouse (8). Total glucose space of the normal islets was $2.64 \pm 0.17 \mathrm{vs}$. 1.22 \pm 0.07 and $1.32 \pm 0.13 \mathrm{nl} / \mu \mathrm{g}$ dry tissue in the untreated and insulin-treated diabetic islets, respectively, $(P$

TABLE IV

Sucrose, Urea, and Glucose Spaces of Islet in Controls, Untreated, and Insulin-Treated Diabetic Rats In Vivo

\begin{tabular}{lccccc}
\hline \multicolumn{1}{c}{ Condition } & $n$ & Sucrose space & Urea space & $\begin{array}{c}\text { Total } \\
\text { glucose space }\end{array}$ & $\begin{array}{c}\text { Intracellular } \\
\text { glucose space }\end{array}$ \\
\hline & & & \multicolumn{4}{c}{$n l / \mu g$ dry tissue } \\
Controls & 8 & $0.60 \pm 0.05^{*}$ & $2.46 \pm 0.20$ & $2.64 \pm 0.17$ & $2.04 \pm 0.11$ \\
$\begin{array}{l}\text { Diabetics } \\
\text { Diabetics } \\
\quad 8\end{array}$ & $0.63 \pm 0.08$ & $2.17 \pm 0.16$ & $1.22 \pm 0.07 \ddagger$ & $0.59 \pm 0.10 \ddagger$ \\
\hline insulin & 8 & $0.69 \pm 0.05$ & $2.64 \pm 0.24$ & $1.32 \pm 0.13 \ddagger$ & $0.63 \pm 0.08 \ddagger$ \\
\hline
\end{tabular}

* Mean \pm SEM of eight animals in each group.

† Significantly different $(P<0.001)$ from the normal animals. 
$<0.001$ for both groups, compared to normal). The intracellular glucose space was also substantially smaller in the diabetic animals (normal 2.04 \pm 0.11 , untreated diabetic $0.59 \pm 0.10$, and treated diabetic 0.63 $\pm 0.08 \mathrm{nl} / \mu \mathrm{g}$ dry tissue, $P<0.001$, for both groups, compared to normal).

Islet ATP, insulin, and glucagon content in normal, untreated, and insulin-treated diabetic animals. Compared to diabetics, normal islets had a small, but significantly higher content of ATP (normal 13.51 \pm 0.15 , untreated diabetic $10.76 \pm 0.30$, and treated diabetic $11.61 \pm 0.22 \mathrm{mmol} / \mathrm{kg}$ dry tissue, $P<0.01$ for both diabetic groups compared to normal) (Table V). Insulin content in both groups of diabetic animals were approximately $3 \%$ of the normal islets, while the glucagon content in the diabetic islets was increased eightfold over that of the normal (Table V).

\section{DISCUSSION}

The present study has uncovered some characteristic features of glucose and energy metabolism of pancreatic $\alpha$-cells. These cells are less accessible to glucose than $\beta$-cells, as indicated by the relatively small intracellular glucose space of $\alpha$-cell islets most readily apparent in the in vivo studies. Further, the ATP content of $\alpha$-cell islets is maintained for prolonged periods in the absence of extracellular glucose in contrast to the mixed islets composed, primarily, of $\beta$-cells, in which the ATP level drops when glucosefree perfusion media are used for sustained periods. Finally, exogenous insulin, at high levels, has no detectable effect on the glucose spaces and only marginal, if any, influence on the ATP content of normal or $\alpha$-cell islets.

Since the present information is derived from steady-state measurements, it is obviously not possible to decide whether glucose or insulin have any effect on the turnover of ATP or whether insulin increases the rate of glucose transport into islet cells. The cardinal question, whether there is an energy shortage of $\alpha$-cells in the diabetic state, seems to be clearly answered, however, by these investigations. There is sufficient ATP and glucose present in the diabetic islet. Since the total glucose content in islets, from streptozotocin-treated rats with a mean plasma glucose of 32.5 $\mathrm{mM}$, measured $43.2 \mathrm{mmol} / \mathrm{kg}$ dry tissue, it follows (based on the information available in Table IV), that the intracellular glucose level in this condition is approximately $15 \mathrm{mM}$. It is well established that extracellular glucose concentrations of this magnitude inhibit stimulated glucagon release almost completely $(5,12,13)$. A similar calculation of the intracellular glucose level in $\alpha$-cell islets after in vitro perfusion with $5 \mathrm{mM}$ glucose is less accurate, since no measurements were made of the extracellular space and because of the relatively high glucose blank of islets
TABLE V

Islet ATP, Insulin, and Glucagon Content in Normal, Untreated, and Insulin-Treated Diabetic Animals In Vivo

\begin{tabular}{|c|c|c|c|}
\hline & ATP & Insulin & Glucagon \\
\hline & mmol/kg dry tissue & $\mu U / \mu g$ dry tissue & $n g / \mu g$ dry tissue \\
\hline Normal & $13.51 \pm 0.15^{*}$ & $1150 \pm 34$ & $3.0 \pm 0.3$ \\
\hline Diabetics & $10.76 \pm 0.30 \ddagger$ & $41 \pm 7 \S$ & $24.0 \pm 1.1 \S$ \\
\hline \multicolumn{4}{|l|}{ Diabetics } \\
\hline+ insulin & $11.61 \pm 0.22 \ddagger$ & $49 \pm 6 \S$ & $22.8 \pm 2.2 \S$ \\
\hline
\end{tabular}

* Mean \pm SEM of eight animals in each group.

$\$$ Significantly different $(P<0.01)$ from the normal animals. $\S$ Significantly different $(P<0.001)$ from the normal animals.

in aglycemic perfusions. However, assuming an extracellular space of $30 \%$ of the total water space $^{3}$ and correcting for the glucose blank, the free intracellular glucose of $\alpha$-cell islets is approximately $2.5 \mathrm{mM}$ in contrast to $5 \mathrm{mM}$ in the normal islets, a concentration of glucose which is sufficient to depress amino acid-stimulated glucagon release in vitro (5). Therefore, it would seem unlikely that a lack of intracellular glucose is the cause of the apparent glucose blindness of the $\alpha$-cells in diabetes. The defect may arise from impaired glucose metabolism or from alterations of putative glucoreceptors on the cell membrane of $\alpha$-cells, to mention just two possibilities.

These considerations are based on the assumption that $\alpha$-cells comprise the major cell type of the microdissected diabetic islet. All evidence available to us at this point indicates that this is a fair assumption; the release data (5), the estimates of islet volume $(5,11)$, the results of hormone measurements in both islets and total pancreas (5), and the comparison of our own functional and chemical data with relevant morphometric data in the literature (9) all indicate that the $\beta$-cells are for all practical purposes eliminated from the islet samples used here for biochemical analyses.

An unsettled question is whether the $\alpha$-cells that remain after streptozotocin- or alloxan-induced $\beta$ cell necrosis are intact, and whether the results obtained here are representative of normal $\alpha$-cells. Nevertheless, the method used here has provided reasonably sound information about some basic biochemical properties of $\alpha$-cells. The $\alpha$-cell energy metabolism seems to be largely independent of the continuous provision of extracellular glucose. Such a characteristic would seem to have survival value since major functional demands on $\alpha$-cells occur during periods of glucose deprivation.

${ }^{3}$ Matschinsky, F. M., A. S. Pagliara, B. A. Hover, C. S. Pace, and J. A. Ferrendelli. J. Biol. Chem. In press. 


\section{ACKNOWLEDGMENTS}

We would like to thank Mrs. Joy Brothers and Ms. Betty Bosch for their technical assistance and Ms. Janet North for typing the manuscript.

This work was supported by U. S. Public Health Service Research grants AM-10591 and AM-17810, and Diabetes and Endocrinology Centers grant AM-17904.

\section{REFERENCES}

1. Raskin, P., Y. Fujita, and R. H. Unger. 1975. Effect of insulin-glucose infusions on plasma glucagon levels in fasting diabetics and nondiabetics. J. Clin. Invest. 56: 1132-1138.

2. Edwards, J. C., and K. W. Taylor. 1970. Fatty acids and the release of glucagon from isolated guinea-pig islets of Langerhans incubated in vitro. Biochim. Biophys. Acta. 215: 310-315.

3. Edwards, J. C. 1973. A-cell metabolism and glucagon secretion. Postgrad. Med. J. Suppl. 49: 611-615.

4. Unger, R. H., and P. J. Lefebvre. 1972. Glucagon physiology. In Glucagon. P. J. Lefebvre and R. H. Unger, editors. Pergamon Press, Inc., Elmsford, N. Y. lst edition. 213-244.

5. Pagliara, A. S., S. N. Stillings, M. W. Haymond, B. A. Hover, and F. M. Matschinsky. 1975. Insulin and glucose as modulators of the amino acid-induced glucagon release in the isolated pancreas of alloxan and streptozotocin diabetic rats. J. Clin. Invest. 55: 244-255.

6. Leichter, S. B., A. S. Pagliara, M. H. Greider, S. Pohl,
J. Rosai, and D. M. Kipnis. 1975. Uncontrolled diabetes mellitus and hyperglucagonemia associated with an islet cell carcinoma. Am. J. Med. 58: 285-293.

7. Matschinsky, F. M., J. V. Passonneau, and O. H. Lowry. 1968. Quantitative histochemical analysis of glycolytic intermediates and cofactors with an oil well technique. J. Histochem. Cytochem. 16: 29-39.

8. Matschinsky, F. M. 1971. Quantitative histochemistry of glucose metabolism in the islets of Langerhans. In Recent Advances in Quantitative Histo- and Cytochemistry. Hans Huber Publishers. Bern Stuttgart, Vienna. 143-182.

9. Hoftiezer, V., and A. M. Carpenter. 1973. Comparison of streptozotocin and alloxan-induced diabetes in the rat, including volumetric quantitation of the pancreatic islets. Diabetologia. 9: 178-184.

10. Lazarus, S. S., and B. W. Volk. 1962. The Pancreas in Human and Experimental Diabetes. Grune \& Stratton, Inc., New York. 83-101.

11. Godfrey, D. A., and F. M. Matschinsky. 1975. Enzymes of the cholinergic system in islets of Langerhans. J. Histochem. Cytochem. 23: 645-651.

12. Gerich, J. E., M. A. Charles, and G. M. Grodsky. 1974. Characterization of the effects of arginine and glucose on glucagon and insulin release from the perfused rat pancreas. J. Clin. Invest. 54: 833-841.

13. Pagliara, A. S., S. N. Stillings, B. Hover, D. M. Martin, and F. M. Matschinsky. 1974. Glucose modulation of amino acid-induced glucagon and insulin release in the isolated perfused rat pancreas. J. Clin. Invest. 54: 819832. 